\title{
Consolidated findings from 6 years research on the age-differentiated design of human- computer interaction
}

\author{
Sebastian Vetter*, Jennifer Bützler, Nicole Jochems and Christopher M. Schlick \\ Chair and Institute of Industrial Engineering and Ergonomics of RWTH Aachen University, Germany
}

\begin{abstract}
The fast aging of many western and eastern societies and their increasing reliance on information technology create a compelling need to reconsider older users' interactions with computers. This paper summarizes the results of 6 years of research on th e age-differentiated desi gn of hu man-computer interaction. The well-known $\mathrm{m}$ odel of human information processing served as the theoretical framework. The model components "sensory processing", "perception", "working memory", "decision and response sel ection" and "response execution" were analyzed exemplarily in task settings on project management. In seven empirical studies with a total number of 405 participants between 20 and 77 years the human-computer interaction was analyzed regarding effectiveness, efficiency and user satisfaction. For $m$ ost but not all studies the results reveal that age-induced differen ces in human-computer inter action can best be compensate d by an ergonomic "design for all". In some cases however an age-specific approach is favorable.
\end{abstract}

Keywords: Human-Computer interaction, interface design, age-differentiated adaptation, aging

\section{Introduction}

The fast aging of many western and eastern societies and their increasing reliance on information technology create a co mpelling $\mathrm{n}$ eed for research and development on older u sers' interactions with c omputers. In Euro pe, for in stance, the population of the EU-27 countries on January 1st, 2010 was estimated to be 501.3 million. The EU population ages at varying s peed. P opulations that are cu rrently the ol dest, such as Germany's and Italy's, will age rapidly for the next twenty years. In 2010, the median age of the EU population was 40.9 years, and it is projected to reach 47.9 year s b y 2060 . The percentage of population aged $65+$ is supposed to increase from $16 \%$ in 2010 to $29.3 \%$ in 2060 [13]. The importance of computer work is increasing likewise. In $2010,52 \%$ of the european wo rking po pulation us es a computer at least one time per week [8].

The literatu re tells u $\mathrm{s}$ th at as $\mathrm{p}$ eople ag e, changes occur in th eir $\mathrm{p}$ erceptual, co gnitive and motor sys- tems th at can $\mathrm{h}$ ave sign ificant effects on th eir performance and well-bei ng [3]. The so called de ficit models dom inated $t$ he $t$ heoretical un derpinning of aging in the past. De ficit models postulate a graceful degradation $\mathrm{i} \mathrm{n} \mathrm{h}$ uman $\mathrm{i}$ nformation processing a nd physical functions fro $\mathrm{m}$ th e late twen ties on [20 ]. However, in recent years, models of aging had to be revised. Nowadays the changes that occur with aging are su bsumed un der $\mathrm{t}$ he s o cal led "c ompensation model" w hich ac knowledges t hat a ge-dependent changes can be compensated by behavioral strategies, by exp eriences an d attitu des, or that the el derly dispose ove $\mathrm{r}$ a $\mathrm{n}$ alternative performance spectrum as compared to the you nger [1]. I $\mathrm{n}$ fact, th e scop e of decrease is highly individual and depends on the abilities under co nsideration and the particular ch aracteristic of the task. Against the background of an aging workforce and the importance of com puter technology to hu man work it is necessary to get a deeper understanding of $\mathrm{t}$ he i nterrelationships between a gerelated ch anges in fun ctional an d physical ab ilities

\footnotetext{
${ }^{*}$ Corresponding author. E-mail: s.vetter@iaw.rwth-aachen.de
} 
and the er gonomic d esign of future work system s. The Germ an Research Foundation ( Deutsche F orschungsgemeinschaft) responded to this gap of scientific kn owledge b y establishing P riority Pr ogramme 1184 on Ag e-differentiated W ork Syste ms in 2005. This i nterdisciplinary basic research pro gramme brings $t$ ogether a $t$ otal of $12 \mathrm{r}$ esearch groups from engineering, psychology and economics with the goal of st udying the i mplications an d e ffects of dem ographic change on human work and developing livespan models to create adequate working and learning conditions for employees of different ages. This paper summarizes the results of 6 years of research focusing on $t$ he a ge-differentiated design a nd e valuation of human-computer interaction. Age related changes were analyzed exem plarily on the basis of a project management soft ware a pplication. C omputer s upported project $m$ anagement is pa rticular i nteresting, as it requ ires co mplex cognitive skills as well as co ordinative-communicative abilities.

The seminal Wickens model of human information processing [30] served as a theoretical framework for the ag e-differentiated an alysis and intervention (Figure 1). Regarding computer work with el ectronic information displays the $\mathrm{m}$ odel elem ents "Sensory Processing", "Perception", "Working Memory", "Decision and Resp onse Selection" and "Response Execution" were thought to have significant contribution to the effectiveness, efficiency and user satisfaction of human computer interaction.

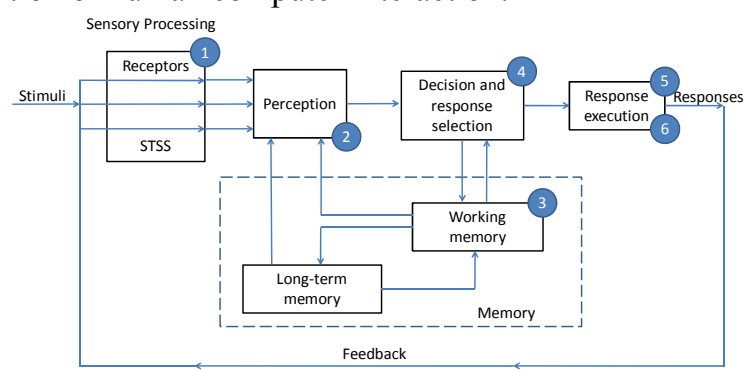

Fig.1: Model of human information processing (Adapted from Wickens [30])

Based on a literature an alysis on ag e-related changes in human inform ation processing six ad aption di mensions wi th high relevance for computersupported pr oject management could be d ifferentiated: (1) angular font size of text and graphical symbols, (2) visualization of net work diagrams, (3) memorization of network diagrams, (4) interpretation of network diagrams, (5) devices for information input and (6) manual information input on large touch screens (for classification to the model of human in- formation processing see numbered el ements in Figure 1).

The first ada ption di mension angular font size of text and graphical symbols refers to the encoding of information on el ectronic information di splays. D ue to ch anges of the $v$ isual syste $m$ the ability to detect and differentiate nearby objects (visual acuity) $n$ aturally deteriorates with increasing age. Although most software syste ms support the user s pecific ada ption of font size, $t$ his feature is rarely use $d$ by elderly computer users.

The sec ond a daption dimension visualization of network di agrams deals with the perc eption of and the navi gation in large gra phical st ructures. It is known $\mathrm{t}$ hat $\mathrm{t}$ he na vigation i $\mathrm{n} \mathrm{c}$ omplex i nformation structures is po tentially strain ing, especially for $t$ he elderly.

The th ird ad aption d imension memorization of network di agrams refers $\mathrm{t}$ o $\mathrm{p}$ ossible age- related changes in memorization of large graphical structures. Since co mputer wo rk primarily addresses co gnitive demands, an age-related decrease in working memory capacity also might have an effect on human performance measures. The state of findings concerning the effect of age on memorization performance of visual objects however is contradictory.

The fo urth adaption d imension interpretation of network di agrams concentrates on possible a gerelated changes in the decision and response selection stages of information p rocessing. In this context interpretation is a general term referring to the mental processing, co mprehension a nd deci sion $m$ aking i n computer s upported $\mathrm{p}$ roject $\mathrm{pl}$ anning wi th network diagrams.

The fifth adaption dimension devices for information inp $u t$ refers to ag e-related ch anges in th e responding stage of i nformation processing. The ag erelated decrease of $m$ otor skills influences the speed and accu racy of inform ation inp ut and po tentially impedes the ease of use of conventional information input devices.

The sixth adaption dimension focuses on the manual information input on large touch screens as th is interaction-technique was found to be beneficial for the performance of many user-groups, particularly for the elderly. However, the regular button size that is used i $\mathrm{n} \mathrm{m}$ any softwa re syste ms is optim ized for mouse input and movements of the hand-arm system are error prone when buttons are located in the upper area of the touch scree $n$. Thus, there is a ne cessity to develop basic concepts for an ergonomic information presentation and input on large touch screens. 


\section{Literature review}

\subsection{Exp. 1: Angular font size of text and graphical symbols}

Eyesight is an ab ility of great i mportance for almost all wo rk system s. Sy mptoms of an ag e-related eyesight de generation process include a re duction of visual acuity, lo ss of power of acco mmodation or reduced c olor pe rception [ 18,25]. A 1 oss of vi sual acuity in particular is often critical with regard to performance and sa fety. Norm al visual acuity is represented by a vi sus value of 1.0 , but it decrease s with age. A 20-year-old normally has a visus between 1.0 and 1.6 whereas an 80-year-old's visus value lies between 0.6 and 1. 0 . The gene ralized decrease in visual acuity of older people is of particular importance when working with electronic information dis plays.

\subsection{Exp. 2: Navigation in network diagrams}

Ergonomic i nformation vi sualization [ 5,7,29] has become an important paradigm for human-computer interaction. There are different approaches to support the navigation in co mplex network d iagrams. In terfaces with an overview map show the details of a network act ivity together with a st ructural overview of the entire chart and can improve subjective sat isfaction [21] and efficiency [2]. By the use of interfaces wh ich provide zoom fun ction the $\mathrm{i}$ nformation space is direc tly visible and can be $\mathrm{m}$ anipulated through $\mathrm{p}$ anning and zo oming. Th e $\mathrm{m}$ ost co mmon zooming technique is the geometric zoom, where the scale linearly determines the apparent size of the object. A fisheye view functions anal ogous to a wi deangle cam era lens, the idea is to s how "local" detail in full (the objects of interest to the user), while displaying successively less detail for information out of the focus of attention.

\subsection{Exp. 3: Memorization of network diagrams}

As stated in the in troductory section, the effect of age on memorization pe rformance of graphical objects is indisti nct. Many a uthors found e vidence for an a ge-related decline i $\mathrm{n}$ m emorization pe rformance of the spatial locations of objects $[24,11,6,14,17,22]$. Other a uthors $\mathrm{h}$ owever c ould not detect age differences in recall per formance of spatial object position [27,12]. In $\mathrm{m}$ ost stu dies on m emorization performance, the expe rimental stimuli are presented in a s equential o rder. T here a re, however, no a gedifferentiated st udies on the memorization performance re garding com plex graphical struct ures as net work diagrams. Based on investigations conducted by Winkelholz and Schlick [32], it was assu med that an improvement of memorization performance will o ccur for horizontally rather $t$ han ve rtically arra nged network diagrams, as well as for a purposeful modification in spatial spread of activities.

\subsection{Exp. 4: Interpretation of network diagrams}

Regarding the in terpretation of co mplex netw ork diagrams it is ass umed that according $t$ o the Proximity Co mpatibility Prin ciple [31 ] a sm all sp atial spread between activities leads to better performance. A positive effect du e to horizontal orientation is also expected in this case [32].

\subsection{Exp. 5: Devices for information input}

Effective, efficient and satisfying human-computer interaction is strongly influenced by the use of input devices. As a result, different input device characteristics pose different requirements on human abilities. Therefore the compatibility between device characteristics and the abilities of the user determines the objective and subjective i nput performance to a large extent. Changes in motor abilities as red uced muscle strength, reduced range of m otion and g reater di fficulty executing fine movements are highly correlated with age [28] and of $\mathrm{m}$ ajor importance for information i nput. $\mathrm{T}$ hus el derly co mputer $\mathrm{u}$ sers may nee $\mathrm{d}$ other input devices than younger users wi th less requirements on $\mathrm{m}$ otor ab ilities an d less com plex $\mathrm{v}$ isuo-motor transformations.

\subsection{Exp. 6: Manual information input on large touch screens}

Large tou ch scr eens provide a pr omising alternative to classic al electronic i nformation di splays in application a reas where one has to display an $\mathrm{d}$ manipulate com plex information at once (plant design, project management, architecture, etc.). Re search has shown that this interaction-technique can be be neficial for many user-groups, particularly for the elderly $[15,19,23]$. The effectivene ss and efficiency of information input however depends highly on the ergonomic design of the user-interface. When redesigning application software originally designed for classical 
desktop computers for large touc $\mathrm{h}$ screens one has to consider wh ere to d isplay men us, buttons or icons, and which size these elements should have in order to improve po inting $\mathrm{p}$ erformance. To determine 'o ptimal' targ et sizes and target po sitions Fitts' Law [10] provides a highly satisfactory model. Fitts' Law states that the movement time $(M T)$ is linearly dependent on the index of difficulty $(I D)$ of a pointing task. The $I D$ is defined as the dyadic logarithm of the quotient of amplitude of the movement $(A)$ and ho rizontal target width $\left(W_{h}\right)$ :

$$
M T=a+b \operatorname{lag}\left(\frac{2 A}{W V}\right)
$$

Fitts' o riginal stu dy on ly co nsidered o nedimensional movements, $\mathrm{h}$ owever o $\mathrm{n} 1$ arge $\mathrm{t}$ ouch screens one has to deal with two-dimensional movements and bivariate targets. As a first step in building a c oncept for the e rgonomic i nformation i nput on large scaled to uch screens Fitts' Law $h$ ad to b e refined regarding two-dimensional pointing of bivariate targets.

\section{Method}

Over the 6 years of research $405 \mathrm{p}$ articipants between 20 and 77 years participated in seven empirical studies reg arding potential ag e-related differences in human-computer interaction.

\subsection{Exp. 1: Angular font size of text and graphical symbols}

The a ge-induced c hange in visual acuity and its impact on performance in a target detection task was investigated in an em pirical study with 75 subjects aged between 20 and 72 years. Subjects were divided into three age groups (AG I: 20 -35, A G II: 4 0-59, AG III: 60-72 years) with 25 persons in each group. Acuity of vision was measured using the standardized eyesight Rodatest 302. In the target detection experiment Lan dolt ri ngs of three di fferent a ngular font sizes (12, 16 and 22 a rc minutes) se rved as target s displayed on a TFT-LCD screen. The participants' task was to react to a Landolt ring with a particular position of opening by pressing the space key. The participant thus $h$ ad to $d$ etect and recognize the previously sp ecified targ et Land olt ring out of a sequence of 120 Landolt rings composed of 15 correct and 105 in correct Landolt $r$ ings. Each $r$ ing was shown for 1.5 seconds. After a five minute break, the procedure was repeated with the next permutation of font size, et ce tera. The number of correctly detected Landolt rings (hits), the number of wrongly detected Landolt rings (false alarms) and the response time of correct $r$ esponses $w$ ere an alyzed $u$ sing an A NOVA with re peated $\mathrm{m}$ easures. $\mathrm{T}$ he relations hip between visus data from Rodatest 302, the participant's age in years an $\mathrm{d}$ th e response tim e in the targ et detection task was analyzed by correlation analysis.

\subsection{Exp. 2: Navigation in network diagrams}

The navigation in complex network diagrams was investigated with 90 participants between 20 and 75 years of age. Su bjects were divided into three age groups (AG I: 20 -39, A G I I: 40 -59, AG I II: 6 0-75 years) with 30 pers ons each. Three different visualisation variants of network diagrams (o verview map, detail wi ndow a nd $\mathrm{z}$ oom fu nction) were $\mathrm{t}$ ested against a network diagram wh ich can be fou nd in many commercial off-the-shelf software packages. In this $\mathrm{v}$ ariant detailed in formation of $\mathrm{t}$ he activities (name, starting time and d uration) was given and the scrolling b ar had to be used to exp lore the n etwork diagrams. In the overview map, the default net work diagram was enric hed by structural inform ation dis played in a n overview window. F or the two other visualization variants $\mathrm{t}$ he $\mathrm{i}$ nformation di splayed on the activities was red uced. Thus, the whole network diagram $\mathrm{w}$ as $\mathrm{d}$ isplayed on th e scr een and scr olling was not $n$ eeded. By t ouching an activity detailed in formation was provided either at a fi xed position in the upper left corner of the screen (detail window) or at the position of the respective activity (zoom function). The experimental task was carried out on a 17" touch screen. The participants had to execute typical project management tasks like cha nging the starting time or duration of an activity and connecting or deleting activities with each of the visualization variants. Execution ti me, errors, scro lling and searc $\mathrm{h}$ tim e as well as su bjective m ental workload (NASA-TLX) were measured as dependent variables.

\subsection{Exp. 3: Memorization of network diagrams}

The memorization of complex net work di agrams was investigated with 90 participants between 20 and 75 years. Subjects were divided into three age groups (AG I : 20 -39, AG II: 4 0-59, A G III: 60 0-75 years) with 30 persons each. Six netw ork diagrams layouts 
depicted in fi gure 2 were displayed on a TFT-LCD computer screen.
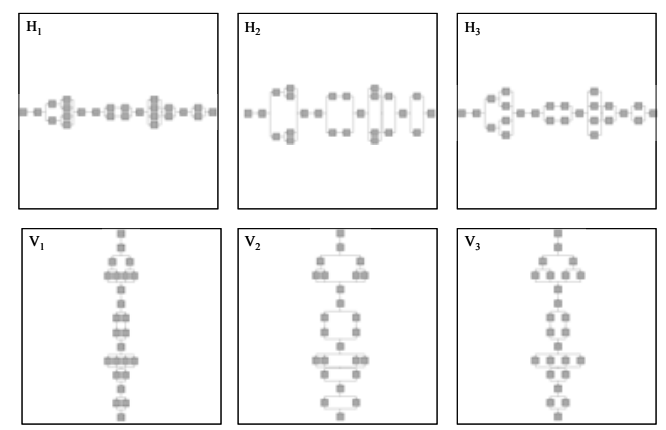

Fig. 2: Six layouts of the network plans.

Each n etwork d iagram con sisted of 25 activ ities. The diagrams di ffered re garding $t$ heir orientation, horizontal ( $\mathrm{H})$ ve rsus v ertical (V), a nd th eir spatia 1 spread: (1 ) n o spread, (2 ) clustered, (3) uniformly spread. After an acoustical signal, a randomly created sequence of fi ve activ ities was h ighlighted by co lor changing. Each activ ity was h ighlighted for two seconds. The end of a sequence was indicated by a second ac oustical signal. $T$ he pa rticipant had $t o$ repeat the sequence by clicking the activities in co rrect order with a mouse. After five activities a short break was obligatory and the next sequence was presented. There were six randomly created sequences for eac $h$ layout. The same six sequences corres ponding to one layout we re presented to each subject. The or der in which the var ious layouts were presented was ba lanced. Execution time and the number of correctly repeated sequences were measured as dependent variables.

\subsection{Exp. 4: Interpretation of network diagrams}

The memorization of complex net work di agrams was inv estigated with th e sa mple of ex periment 3 . The six network diagram layouts depicted in figure 2 were used in a simplified form. Additionally, the start and end times for each activity were displayed within the diagram (see figure 3).

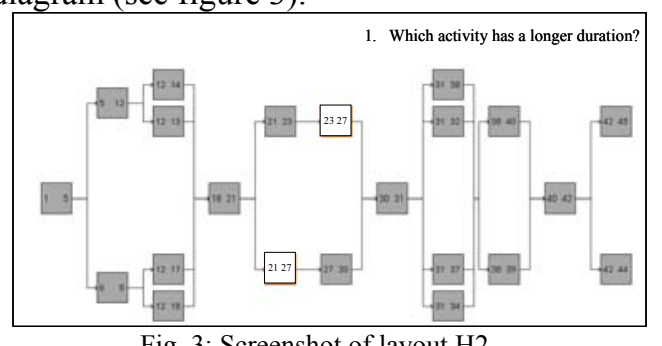

After an aco ustical si gnal, one o r t wo randomly chosen activities were highlighted. After two seconds, one of the following four questions c oncerning the highlighted activ ities ap peared: (1) "Which activity has a l onger duration?", (2) "Which act ivity end s first?", (3) "How many direct predecessors does this activity have?" (4) "How many direct s uccessors does this activity have?". The subject had to answer the question by $\mathrm{m}$ arking the correct activity, res pectively, the correct number, by mouse click. Then the next question was presented. Each test subject had to answer identical questions in the sam e sequence per layout. The order in which the various layouts were presented was balanced between test subjects. Execution time and the number of correctly answered questions were measured as dependent variables.

\subsection{Exp. 5: Devices for information input}

Three inpu t devices, (1) m ouse, (2) tou ch scr een and (3) eye-gaze control, were c ontrasted with one another on the basi s of a $t$ wo-dimensional poi nting task. A to tal of 90 subjects between 20 and 75 years participated in the study. Subjects we re divided into three age groups (AG I: 20-39, AG II: 40-59, AG III: $60-75$ years) with 30 persons each. The pointing task had to be executed with each of the three input devices as fast and accurately as possible. When using the mouse, the cursor had to be positioned in the starting circle first and then moved to the target square. The start and target positions had to be confirmed with a mouse cl ick. When using the touch screen, the task consisted of touching the starting circle, followed by touching the target square with the index finger. For the eye-gaze control, the task required first to visually fixate on a point within the starting circle and then to fixate the target sq uare. The fix ation dwell ti me on the targ et obj ect was set $\mathrm{t}$ o $100 \mathrm{~m} \mathrm{~s}$. The execution time and the error rate were dependent variables.

\subsection{Exp. 6: Manual information input on large touch screens}

In the first study [26] the two most common target width defi nitions $W_{\min }$ an $\mathrm{d} W^{\prime}$ we re a nalyzed in an empirical study with 30 right-handed subjects (20-73 years) i n a pointing task on a la rge scaled touc $h$ screen (projection area $865 \mathrm{~mm}$ x $649 \mathrm{~mm}, 4: 3$ ratio). Subjects were di vided $\mathrm{i}$ nto $\mathrm{t}$ wo a ge gr oups (AG I: 20-32, AG II: 58-73) with 15 pe rsons each. The experimental task s howed rectangular target ob- 
jects at a constant angle of $0^{\circ}$ (movement to the right) which were rotated ar ound their ce ntre. Hereby, $W^{\prime}$ was varie d systematically, whereas $W_{\min }$ was kept constant.

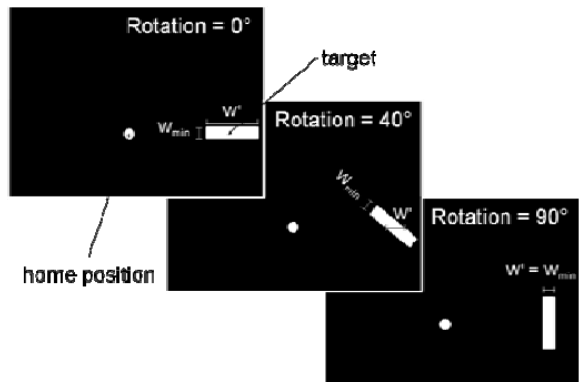

Fig. 4. Experimental setting for target rotations of $0^{\circ}, 40^{\circ}, 90^{\circ}$.

In the second study [4] the motion angle was investigated with 30 participants aged between 21 to 77 years. Subjects w ere divided i nto t wo age gr oups (AG I: 21-36, AG II: 58-77) wi th 15 persons each. The angle between start -and target object was varied systematically in $10^{\circ}$ steps between $0^{\circ}$ (movements to the right) and $180^{\circ}$ (movements to the left). To eliminate $i$ nfluences of $t$ he $t$ arget wi dth, ci rcular $t$ arget objects were used.

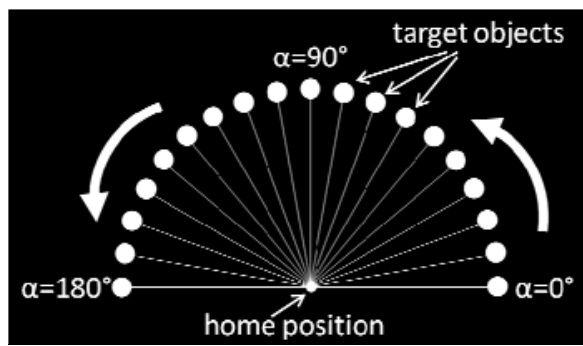

Fig. 5. Experimental setup for a start position at $0^{\circ}$.

The mean response time of c orrect responses was calculated as a dependent variable.

\section{Results}

According to the ex perimental desi gns t he dat a was a nalysed by a nalyses of va riance with re peated measures (ANOVA), correlation a nalyses and linear as well as nonlinear regression a nalyses. The si gnificance level for e ach analys is was $\mathrm{p}=0.05$. For si $\mathrm{g}$ nificant $m$ ain effects the effect size $\omega^{2}$ for $r$ epeated measures [9] was c alculated. Only $m$ ain results a re reported. For a detailed analysis the reader is referred to the original publications.

\subsection{Exp. 1: Angular font size of text and graphical symbols}

The results from an ANOVA show a strong effect of font size $\left(\omega^{2}=0.73\right)$ and a medium age-related effect $\left(\omega^{2}=0.48\right)$ co ncerning the $r$ esponse time of cor rect responses. The interaction effect of font size and age group $\left(\omega^{2}=0.10\right)$ sh ows t hat age-related di fferences in re sponse time can be com pensated by enlarging the a ngular font si ze from $16 \mathrm{t}$ o 22 arc $\mathrm{mi}$ nutes. Results from $\mathrm{p}$ artial co rrelation an alysis show that an ag e-differentiated adap tation of font size is recommended rathe $\mathrm{r} t$ han an a daptation base $\mathrm{d}$ on measurement of visual acuity.

\subsection{Exp. 2: Navigation in network diagrams}

The ANOVA of the execution time across all visualization variants shows a signi ficant main effect of age group with a medium effect size of $\omega^{2}=0.66$. The visualization varian $t$ also has a significant effect on the execution time with a large effect size of $\omega^{2}=0.91$. Furthermore, the data show that for the 20-39 y earolds and 40-59 year-olds the shortest average execution times are reached by work ing with th e d etail window whereas the eld erly participants $(60-75$ year olds) performed best when using the zo om function. Regarding the $\mathrm{n}$ umber of e rrors, the ANOVA indicated significant effects of a ge group $\left(\omega^{2}=0.23\right)$ and visualization variant $\left(\omega^{2}=0.13\right)$. The lowest error rate was found for the detail window and zoom function. The control va riant leads to longest sea rching tim es and the reduced network diagram with zoom function to th e sh ortest. Scro lling time is sh orter with the overview window co mpared to th e con trol $\mathrm{v}$ ariant. Regarding the subjective evaluation of mental workload the zoom function leads to the least and the control layout to the highest workload.

\subsection{Exp. 3: Memorization of network diagrams}

For the number of correctly memorized sequences as well as th e overall ex ecution time ANOVAs con firmed signifi cant age e ffects $\left(\omega^{2}=0.32 ; \omega^{2}=0.25\right)$, with $\mathrm{t}$ he hi ghest $\mathrm{m}$ emorization performance in $\mathrm{t}$ he group of the 20-39 year olds. The results of the layout design of the network diagrams show si gnificant effects of spread ( $\left.\quad \omega^{2}=0.68\right)$ o $\mathrm{n}$ exec ution $\mathrm{t}$ ime $\left(\omega^{2}=0.15\right)$ a nd num ber of correctly repe ated sequences $\left(\omega^{2}=0.68\right)$. The layou ts "cluster spread" and 
"uniformly di stributed s pread" are beneficial for memorization performance ( high am ount of c orrect answers, low amount of required time). The 1 ayout without spread scores si gnificantly lower. Regarding the orientation of the network diagram, a h orizontal layout sc ores significantly $\mathrm{h}$ igher $\mathrm{t}$ han $\mathrm{t}$ he vert ical layout $\left(\omega^{2}=0.70\right)$.

\subsection{Exp. 4: Interpretation of network diagrams}

Since there was v ery little $\mathrm{v}$ ariance in the number of c orrectly a nswered questions as al most no er rors occurred, only the results of the response time were analyzed with an ANOVA. The results reveal that the age group $\left(\omega^{2}=0.41\right)$ and the spatial spread $\left(\omega^{2}=0.27\right)$ of the $n$ etwork activ ities $h$ ave sign ificant effects on response time. Post-hoc paired comparisons of means showed sign ificant differences bet ween all a ge groups. Response time increases with increasing age. Regarding the spatial spread, it was found that equally $\mathrm{d}$ istributed spread lead to sho rter response tim es than a cl uster spread or a layout without spread. However, spatial ori entation of the network diagram had no significant effect on response time.

\subsection{Exp. 5: Devices for information input}

The ANOVA of the execution times across all input devices shows a significant main effect in relation to age group $\left(\omega^{2}=0.55\right)$. Post-hoc paired comparisons of $m$ eans showed significant differe nces betwee $n$ AG I and AG II as well as between AG I and AG III. The input device also has a significant effect on execution time $\left(\omega^{2}=0.51\right)$. The touch screen leads to significantly better performance than the eye-gaze control an $\mathrm{d}$ mouse in put. Furthermore, a si gnificant interaction effect between a ge group and input device occurs. Th e data show $t$ hat the a verage execution times of AG II and A G III differ sig nificantly only for mouse input.

\subsection{Exp. 6: Manual information input on large touch screens}

Linear regression a nalysis shows that the movement time varies as a function of the target width in the direction of motion $\left(W^{\prime}\right)$. Furthermore, significant effects of the target height perpendicular to the direction of motion $\left(H^{\prime}\right)$ were found. The best empirical fit was found for a model taking into account the target width in the direction of motion ( $W^{\prime}$ ) and the target height perpendicular to the direction if motion $\left(H^{\prime}\right)$ :

$$
\mathrm{MT}=a+b \log _{a}\left(\frac{A}{\mathrm{r}}+1\right)+c \log _{a}\left(\frac{A}{\mathrm{a}}+1\right) .
$$

The results of the second study reveal that movement $t$ ime fol lows a si nusoidal $c$ urve de pending on the angle. Based on the results of both studies a model for two-dimensional pointing and bivariate, rectangular target objects was derived:

$$
\begin{aligned}
& \mathrm{MT}=a+b \log _{2}\left(\frac{A}{w}+1\right)+c \log _{2}\left(\frac{A}{H}+1\right)+ \\
& \text { d. } \sin (2 a)
\end{aligned}
$$

The formulas (2) and (3) are based on the Shannon formulation [16] by MacKenzie and Buxton.

\section{Discussion}

For a detailed discussion of the results in the lig ht of the literatu re the reader is referred to the original papers. Because of limited space the results are broken down in consolidated "take home messages" for the age-differentiated design of HCI as follows:

- Elderly c omputer u ser do be nefit from a 1 arger font size. In most cases it is not nec essary to measure visual acuity, but simply to enlarge angular font size based on age up to 22'.

- If possible, reduce information displayed at once by the use of zoom functions. El iminate or reduce scrolling activities.

- Arrange network diagrams (or similar graphical models) ho rizontally. Reg arding th e spatial spread of activ ities it dep ends on th e task. If memorization is $\mathrm{m}$ ore im portant, use a 1 arge cluster spread, if in terpretation do minates, choose a narrow equally distributed spread.

- Use touch screens for the elderly. For physically impaired c omputer user ey e gazed input is a promising alternative.

- When designing software for large touch screens, the refined Fitts' Law can b e used to determine an 'optimal' angular position of buttons and interaction el ements. Furthermore, the model can be used a priori to calculate the best proportions of the si de 1 engths for buttons a nd i nteraction elements depending on the angle. 


\section{Acknowledgement}

The research was funded by the German Research Foundation acco rding t o th e Priority Pro gram No . 1184, Age-differentiated Work Systems.

\section{References}

[1] P. B. Baltes, A psychological model of successful aging. Keynote Lecture, World Congress of Gerontology, 2005, Brazil.

[2] D. V. Bea rd and J. Q. Walk er, Navigational techni ques to improve the display of large two-di mensional spaces, Behaviour \& Information Technology 9, (1990), pp. 451-466.

[3] J. E. Birren and K. W. Schaie, Handbook of the Psychology of Aging. 6th Edition. Academic Press, 2005.

[4] J. Bützler, S. Vetter, N. Jochems, and C. Schlick, C., Refinement of Fitts' Law for La rge Touch Sc reens: AgeDifferentiated Analysis of the Motion Angle in $\mathrm{Bi}$ variate Pointing Tasks. Proceedings of Hum an Factors in O rganisational Design and $\mathrm{M}$ anagement-X, 2, 2011, Gr ahamstown, South Africa: IEA Press, Santa Monica, California, pp. 93-99.

[5] S. K. Card, J. D. Mackinlay and B. Shneiderman, Readings in information visualization. Using visi on to thin $\mathrm{k}$. The Morgan Kaufmann Ser ies in Interactive Technolo gie, San Fr ancisco, Calif., 1999.

[6] N. Char ness, Vis ual shor t-term memory and aging in chess players. Journal of Gerontology, 36, (1981), pp. 615-619.

[7] C. Chen, Information Visualisation and Virtual Environments. London: Springer-Verlag, 1999.

[8] Eurostat. Database on Co mputers an d the I nternet in households and enterprises, 2011. h ttp://epp.eurostat.ec.europa.eu/ portal/page/portal/information society/data/database

[9] A. Field, Discove ring Statistics Usi ng SPSS. Sage P ublications, 2009.

[10]P. M. Fitts, The information capac ity of the hu man motor system in controll ing the a mplitude of movement. Journal of Experimental Psychology, 47, (1954), pp. 381-391.

[11] W. J. Hoyer and J. M. Rybash, Age and visual field di fferences in co mputing spatial $r$ elations. Psy chology and Aging, 7, (1992), pp. 339-342.

[12]K. C. Kirasic, Spatial Cognition and Behavior in Young a nd Elderly Adults: Implications for Learning New Environments, Psychology and Aging, 6, 1, (1991), pp. 10-18.

[13] G. Lanzierie, The gr eying of the baby boo mers. A centur ylong view of ageing in European populations. Eurostat, statistics in focus, 23, 2011, pp. 1-11.

[14]L. L. Light and E. M. Zelin ski, Memory for sp atial information in y oung and old adults. Developmental Psychology, 19, (1983), pp. 901-906.

[15]H. Luczak, C. Schlick, N. Jochems, S. Vetter and B. Kausch, Touch Scr eens for the E lderly: Som e Models and M ethods, Prototypical Develop ment and E xperimental E valuation of Human-Computer Interaction Concepts for the Elderly, In: D. Haftor, A. Mirijamdotter, eds., Information and Co mmunication $\mathrm{T}$ echnologies, Society and $\mathrm{Hu}$ man Beings: $\mathrm{T}$ heory and Framework, I GI Global, Her shey, Pennsylvania, 2010, pp. $116-135$.

[16]S. M acKenzie and W. Buxton, Extending Fitts' law to twodimensional tasks, in: Conference on Hu man Factors in Computing Systems, P. Bauersfeld, J. Bennett, and G. Lynch, eds. California, United States, ACM, 1992, pp. 219-226.
[17]T. E. Moore, B. R ichards and J. Ho od, Aging and the codin g of spatial information. Journal of Gerontology, 39, (1984), pp. 210-212.

[18]P. M ouroulis, Visual I nstrumentation Handboo k: Optical Design and Engineering Principles, 1999, Mc Graw-Hill.

[19]A. Murata and H . Iw ase, Usability of touch-panel int erfaces for older adults, Human Factors, 47, (2005), pp. 766-776.

[20]G. N aegele, Zwis chen Arbeit und Rente: Gesellscha ftliche Chancen und Risi ken älter er Arbeitnehmer, 2004, Augsburg: Maro-Verlag. (in german)

[21]C. Nor th and B. Shneiderm ann, Snap- together visualization: evaluating coor dination usage a nd construction. International Journal of Human-Computer Studies, 53, (2000), pp. 715-739.

[22]K. Pezdek, Memory for ite $\mathrm{ms}$ and $\mathrm{t}$ heir spatial locati ons by young and elder ly adults. De velopmental Psychology , 19, (1983), pp. 895-900.

[23]P. Rau and J. Hs u, I nteraction devices and web design for novice older users. Educational Gerontology, 31, 1, (2005), pp 19-40.

[24] M. J. Sharps and E. S. Gollin, Memory for Object Locations in Young an d E lderly Adults. Jour nal of Ger ontology, 42, 3, (1987), pp. 336-341.

[25]F. Slataper, Age $\mathrm{n}$ orms of ref raction and vision, Archi ves of Opthalmology, 43, (1950), pp. 466-481.

[26] S. Vet ter, J. Bützler, N. Joc hems and C. Schlick, Untersuchungen zum Fitts'schen Gesetz anhand eines großflächigen $\mathrm{T}$ ouch-Displays, in: I nnovative Interaktionstechnologien für Mensch-Maschine-Schnittstellen, 52. Fachausschu sssitzung Anthr opotechnik der DGL R Lilienthal-Oberth e.V., Berlin, D GLR e.V., M. Grandt and A. Bauch, eds., Bonn, 2010, pp. 147-158. (in german)

[27] K. J. Waddell and B. Rogoff, Effect of contextual organization on spatial memory of middle-aged and older wo men. Developmental Psychology, 17, (1981), pp. 878-885.

[28]N. Walker, D. A. Philbin and C. Spruell, The use of signal detection theory in research on age- related differ ences in movement control, in: Aging and S killed Perform ance. Advances in Theory and Applications. W. A. Rogers, A. D. Fisk and N. Walker, eds., Lawrence Erlbaum Associates, 1996, pp. 45-64.

[29]C. Ware, I nformation V isualization: Perception for Design, 2000, Academic Press.

[30]C. D. Wickens, Engineer ing Psy chology and Hu man Performance, 1992, HarperCollins Publishers.

[31]C. D. Wickens and M. Carswell, The proximity compatibility principle: I ts psy chological fo undation and $r$ elevance to display design. In: Human Factors, 37, 3, (1995), pp. 473-494.

[32] C. Winkelholz and C. Schlick, Modeling human spatial memory within a sy mbolic architect ure of cognition, i n: Spatial Cognition V, Lect ure Notes in Artificial Intelligence, T. Barkowsky, ed., 2007, Ber lin, Heidelb erg: Spr inger Ver lag, pp. 229-248. 